\title{
Characterizing residence patterns of North Atlantic right whales in the southeastern USA with a multistate open robust design model
}

\author{
A. M. Krzystan ${ }^{1, *}$, T. A. Gowan1, W. L. Kendall' ${ }^{2}$, J. Martin ${ }^{3}$, J. G. Ortega-Ortiz ${ }^{4}$, \\ K. Jackson ${ }^{1}$, A. R. Knowlton ${ }^{5}$, P. Naessig ${ }^{6}$, M. Zani ${ }^{5}$, D. W. Schulte ${ }^{6}$, C. R. Taylor ${ }^{6}$ \\ ${ }^{1}$ Florida Fish \& Wildlife Research Institute, St. Petersburg, FL 33701, USA \\ ${ }^{2}$ U.S. Geological Survey, Colorado Cooperative Fish and Wildlife Research Unit, Fort Collins, CO 80523, USA \\ ${ }^{3}$ U.S. Geological Survey, Wetland and Aquatic Research Center, Gainesville, FL 32653, USA \\ ${ }^{4}$ University of South Florida, College of Marine Science, St. Petersburg, FL 33701, USA \\ ${ }^{5}$ New England Aquarium, Boston, MA 02110, USA \\ ${ }^{6}$ Sea to Shore Alliance, Sarasota, FL 34233, USA
}

\begin{abstract}
Effective conservation of endangered North Atlantic right whales Eubalaena glacialis requires information about their spatio-temporal distribution. Understanding temporal distribution is particularly important, because a portion of the population migrates between high-latitude summer feeding grounds off the northeastern US and Canadian Maritimes coasts and lower-latitude calving and wintering grounds off the southeastern US coast (SEUS). Here, we modeled SEUS residence patterns using photo-identification data from coastal South Carolina, Georgia, and Florida from 7 winter seasons (2004/2005-2010/2011). We used multistate open robust design models to evaluate effects of reproductive status, demographic group, and environmental conditions on SEUS residence. Model estimates accounted for temporal variation and imperfect detection and provided probabilities of entering the SEUS, staying in the SEUS, and being sighted in the SEUS. We also derived estimates for residence time and seasonal abundance. We observed staggered arrival and departure patterns and demographic differences in residence patterns that are characteristic of a differential migration strategy. Calving females arrived earliest and, in most seasons, had mean residence periods more than twice as long as other demographic groups. Conversely, adult males arrived the latest and had the shortest residence times. Within-season detection was positively influenced by survey effort, and overall seasonal mean $( \pm \mathrm{SE})$ detection rate estimates ranged from $0.83 \pm 0.08$ for non-calving adult females to $0.98 \pm 0.02$ for calving females. Results provide insights into right whale behavior, biology, and temporal distribution in the SEUS and can be used to evaluate spatially and temporally dynamic management measures.
\end{abstract}

KEY WORDS: Mark-recapture · Open robust design · Phenology $\cdot$ Residence $\cdot$ Eubalaena glacialis North Atlantic right whale

\section{INTRODUCTION}

Despite protection since 1935, endangered North Atlantic right whales Eubalaena glacialis remain vulnerable to human-related threats along the industrialized Atlantic coast of North America (NMFS

${ }^{*}$ Corresponding author: andrea.krzystan@myfwc.com
2005). Primary causes of serious injury and mortality are ship strikes and fishing gear entanglements (Knowlton \& Kraus 2001). Reducing deaths and serious injuries from these threats is the focus of conservation efforts and regulatory measures to support population recovery (NMFS 2005). Conservation Attribution Licence. Use, distribution and reproduction are unrestricted. Authors and original publication must be credited. 
efforts include aerial surveys to mitigate ship strikes by notifying mariners about whale locations as well as monitoring programs that provide right whale sighting information to monitor population status, habitat use, and the effectiveness of regulatory measures (Brown et al. 2007). Regulatory measures to reduce encounters between right whales and ships or fishing gear include fishery time-area closures (Farmer et al. 2016), vessel routing schemes (Vanderlaan \& Taggart 2009), and time-area vessel speed restrictions (Conn \& Silber 2013).

These measures are implemented seasonally in high-latitude summer feeding grounds along the northeastern United States and Canadian Maritimes coasts and lower-latitude calving and wintering grounds in the southeastern United States (SEUS), which have been identified as critical habitat areas based on their ecological importance and the current understanding of right whale distribution and movement patterns (Winn et al. 1986, NMFS 2014). However, an incomplete understanding of variation in right whale distribution among aggregation areas complicates the development of effective management and conservation strategies (Schick et al. 2013). In fact, limited knowledge of right whale migration timing and residence duration in critical habitat areas has contributed to a lack of comparable protective measures and monitoring efforts along the midAtlantic coast (Firestone et al. 2008), which is the presumed migratory corridor for the annually variable portion of the right whale population that migrates seasonally between high-latitude feeding grounds and the SEUS (Kraus et al. 1986, Winn et al. 1986). An improved understanding of when and where right whales aggregate is necessary to design conservation and management actions that support population recovery (Vanderlaan \& Taggart 2009, Farmer et al. 2016).

Although descriptions of right whale distribution and movement patterns are available, there are few quantitative studies of North Atlantic right whale residence timing within high-use or critical habitat areas. Since direct estimates of residence time from tagging are limited, most estimates of arrival and departure times and total residence time within a given habitat are based on the first and last sighting dates of individual whales identified from photographed sighting events (e.g. Burnell \& Bryden 1997, Mayo et al. 2004, Fortune et al. 2013). Other approaches have quantified SEUS residence and departure timing by modeling frequency distributions of individual resighting histories (Hiby \& Leaper 2005) or with linear regression modeling of aggregated sighting data (Firestone et al. 2008). Hiby \& Leaper (2005) estimated a modal departure date from Jacksonville, FL, of the third week in February and predicted later departure in years with more calves present, while Firestone et al. (2008) predicted a later modal departure date of 2-11 March from Jacksonville, FL, and that almost all whales departed the calving grounds by the end of March. These estimates are consistent with the generally accepted migration model where right whales arrive in the SEUS in the fall and leave the SEUS in the spring (Winn et al. 1986), but do not account for imperfect detection, survey effort influences, or demographic differences beyond calf presence or absence. Not accounting for imperfect detection can lead to incorrect inferences or ineffective management decisions due to biased estimates (Gu \& Swihart 2004). These issues can be addressed with capture-recapture models, which use encounter histories of identifiable individuals from multiple sampling periods to estimate population parameters while accounting for imperfect detection and have been used to estimate residence timing for southern right whales (Fewster \& Patenaude 2009).

Here, we apply a multistate open robust design capture-recapture model (Kendall \& Bjorkland 2001, Kendall et al. in press) to 7 seasons (2004/2005 to 2010/2011) of right whale photo-identification data for the SEUS wintering area. Our objectives were to describe the phenology and duration of right whale residence in the SEUS while accounting for imperfect detection and to assess variability in residence patterns across winter seasons; among life history states defined based on age, sex, and reproductive class; and in relation to environmental covariates. Specifically, we hypothesized that the duration of residency would vary across demographic groups due to differences in life history and energy requirements, with calving females having the longest SEUS residency to support calf development. Additionally, we hypothesized that right whales would reside in the SEUS for more time during cold winters, but for less time following years of low prey availability, to meet energetic demands. We also provide the first estimates of winter right whale abundance in the SEUS that account for differences in detection across demographic groups. Quantifying phenology, residency, and abundance for ecologically important areas like the SEUS provides insight into the biology of this highly mobile species, while also informing monitoring and management actions to mitigate impacts from ship strikes and entanglements. In particular, knowledge of the phenology and duration of residence can increase the effectiveness of management 
actions by identifying the appropriate timing and extent of monitoring surveys and protective measures (Bowlin et al. 2010, Bunnefeld et al. 2011); inform risk assessments by identifying when whales may be exposed to threats outside of existing protected areas (NMFS 2005); and inform marine spatial planning to manage impacts to whales while minimizing economic and social costs (Petruny et al. 2014).

\section{MATERIALS AND METHODS}

\section{Right whale data}

Within the SEUS wintering grounds, systematic aerial surveys have been conducted from approximately December to March since 1994 through the multi-agency Early Warning System (EWS) aerial survey and communication network (Brown et al. 2007). Although the objectives, level of effort, spatial extent, and configuration of these surveys have varied, all surveys consisted of daily (weather-

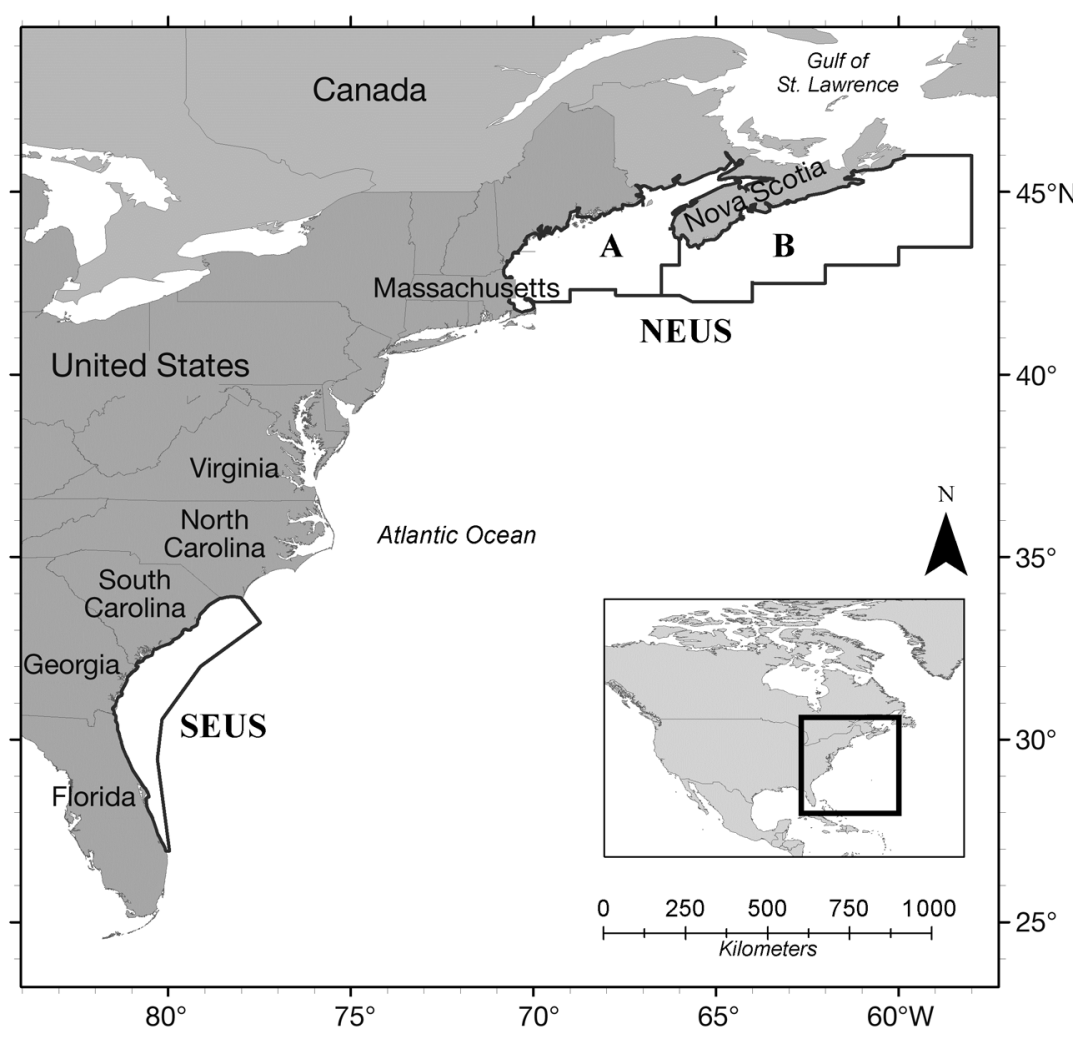

Fig. 1. Southeastern United States (SEUS) study area and area boundaries used to summarize environmental covariates in the northern right whale habitats (NEUS). The NEUS-A area contains right whale habitats in the Bay of Fundy, Gulf of Maine, Grand Manan Banks, Jeffrey's Ledge, Cape Cod Bay, and Massachusetts Bay, and the NEUS-B area includes habitats on the East Scotian Shelf and Roseway Basin permitting) visual survey flights of up to 4 fixed-wing aircraft. Survey teams documented right whale Eubalaena glacialis sightings and collected high-quality photographs of whales and their callosity patterns, scars, and other distinguishing characteristics or markings, which uniquely identify individual whales (Payne et al. 1983, Kraus et al. 1986). Photographed sightings from aerial surveys, along with sightings from opportunistic and other research platforms, were integrated within the North Atlantic Right Whale Consortium (NARWC) Identification database (Hamilton et al. 2007), which is curated by the New England Aquarium. The Identification database also contains genetic information for individual identification from skin biopsies collected during vessel surveys, which are paired with photos of the sampled individuals (Frasier et al. 2007, 2009).

For this study, we obtained photo-identification records from the Identification database (accessed 14 February 2014; NARWC 2014) and analyzed sighting records from south of the North Carolina/South Carolina border for 7 winter seasons: 2004/2005 to 2010/2011. This study area (SEUS region, Fig. 1) is part of the South Atlantic Bight, which is characterized by a broad continental shelf ranging from $\sim 10$ to $\sim 120 \mathrm{~km}$ wide (Blanton et al. 2003) and a gently sloping topography interspersed with areas of hard bottom habitat (Good 2008). We defined a winter season from November to April, since aerial surveys were expanded to these months in some years. This study area and range of years had relatively consistent aerial survey coverage of nearshore waters from the central east coast of Florida to approximately North Myrtle Beach, South Carolina (Good 2008, Gowan \& Ortega-Ortiz 2014), thus reducing heterogeneity in detection probability.

Individual photo-identification records included sighting date and location, descriptions of observed associations, a unique identification, and age class and gender information. This information was used to assign whales into 5 demographic groups for each winter season: calving or noncalving adult females, adult males, juveniles, or unknown age/sex. Sex was determined based on observation of the genital area, close association 
with a calf, or genetic information (Brown et al. 1994). Whales were considered adults when they had a known age or sighting history of at least 9 yr or, for females, after having their first calf (Hamilton et al. 1995). Individuals of any sex class (male, female, or unknown) were classified as juveniles if they were first identified as calves and had a known age < 9 yr. Individuals were classified as calving females based on close association with a calf (Knowlton et al. 1994) at any point during the winter season. Since demographic group classifications were constant within seasons, the calving female group included both females that were seen with a calf at their first sighting in the SEUS and females that were first seen without a calf and then later with a calf in the same season. We assumed whales were classified as calving females without error because the intensive survey effort and nearshore tendency of whales in the SEUS allows observers to reliably identify the presence of a calf (Browning et al. 2010). Calves or yearlings still associated with their mothers were excluded from the analyses to prevent pseudoreplication.

\section{Data analysis}

Multistate open robust design model

We modeled the phenology and duration of right whale winter residence in SEUS coastal waters using multistate open robust design capture-recapture models (MSORD; Kendall 2004, Kendall et al. in press). The MSORD model structure includes parameters for arrival, detection, and persistence probabilities across secondary sampling periods (e.g. weeks) within a series of primary sampling periods (e.g. years), in addition to survival probabilities and probabilities of transition among states between each successive primary period. However, in this application, we ignore survival and state transitions and use only the within-season part of the model structure to characterize right whale residence.

For this study, primary periods were the 7 winter seasons (hereafter seasons) from 2004/2005 to 2010/ 2011, and secondary periods consisted of eleven $14 \mathrm{~d}$ time periods (henceforth referred to as biweeks) from 15 November to 17 April (or 16 April in 2007/2008). We chose a biweekly secondary period to balance the number of parameters estimated relative to the amount of available data. Sighting histories were compiled for these time periods from photo-identification records by determining if an individual was identified at least once during each biweek in each season.
For each season and life history state (calving females, non-calving adult females, adult males, juveniles, and unknown age/sex), we estimated parameters pent $_{j}$, the probability an individual arrives in the SEUS in biweek $j_{i} p_{j}$, the probability an individual present in the SEUS in biweek $j$ is detected; and $\varphi_{j}^{(v)}$, the probability an individual in the SEUS in biweek $j$, which has been in the study area for the previous $v$ biweeks, is still in the study area in biweek $j+1$. The probabilities of entry and detection probabilities can be modeled as a function of state, covariates, or time. Persistence can be modeled as a function of these factors and as a function of the number of biweeks since first arrival in the study area (i.e. the time since arrival). Moreover, pent $_{j}$ is conditional on those that use the study area for at least 1 time period and, therefore, must sum to 1.0 across all $l_{t}$ biweekly sampling periods each season $\left(l_{t}\right)$ :

$$
\sum_{j=1}^{l_{t}} \text { pent }_{j}=1.0
$$

An example model structure for a study that includes 3 time periods and has a detection history of 011 ( 1 for detection and 0 for non-detection in each period) is:

$$
\text { pent }_{1}\left(1-p_{1}\right) \varphi_{1}^{(0)} p_{2} \varphi_{1}^{(1)} p_{3}+\text { pent }_{2} p_{2} \varphi_{2}^{(0)} p_{3}
$$

where the individual is first detected in sampling Period 2 and continues to be detected in Period 3, but could have entered in Period 1 and was not initially detected.

From the MSORD model structure, we also used 2 derived parameters for each life history state and season $t$ : abundance and residence time. The total abundance of whales in each life history state that utilized the SEUS in season $t, N_{t}^{*}$, was estimated as $\hat{N}_{t}^{*}=n_{t}^{*} / \hat{p}_{t}^{*}$, where $n_{t}^{*}$ is the number of individuals of a given state sighted at least once within the season (Kendall 2006, Kendall et al. in press). Effective capture probability $p_{t}^{*}$ is the probability that an individual in the SEUS in season $t$ is sighted at least once during the season, which is, in turn, a function of the various model parameters pent $t_{j}, p_{j}$, and $\varphi_{j}^{(v)}$. The total expected residence time in the study area for each state and season $t, R_{t}$, was estimated as a weighted average of biweekly periods, weighted by the probability that an individual is in residence for exactly that duration. For example, for a season of 3 sampling periods, the expression would be:

$$
\begin{gathered}
R_{t}=1 \times\left[\text { pent }_{1}\left(1-\varphi_{1}\right)+\text { pent }_{2}\left(1-\varphi_{2}\right)+\text { pent }_{3}\right] \\
+2 \times\left[\text { pent }_{1} \varphi_{1}\left(1-\varphi_{2}\right)+\text { pent }_{2} \varphi_{2}\right] \\
+3 \times\left[\text { pent }_{1} \varphi_{1} \varphi_{2}\right]
\end{gathered}
$$


(Kendall 2006, Kendall et al. in press). The delta method was used to estimate variances for $N_{t}^{*}, R_{t}$, and $p_{t}^{*}$.

The model assumes closure (i.e. no changes in occupancy due to births, deaths, immigration, or emigration) of the population among biweeks and that members of the population enter and exit the study area just once each season. Given that right whales are long-lived, large mammals (Brown et al. 2009) and that calf sighting data were not modeled, closure assumptions related to births and deaths are reasonably met. However, movement into or out of the study area more than once within a season is possible because surveys do not cover the entire area potentially available to right whales in the SEUS (e.g. offshore waters) and long-distance travel has been observed for right whales within periods as short as 2 wk (Mate et al. 1997). Nevertheless, completely random movement in and out of the study area within the season would not bias estimates of arrival or persistence probabilities and would simply reduce the effective sighting probability (Kendall 1999). Another assumption is that whales do not arrive before or depart after the duration of sighting effort; violation of this assumption would require interpretation of residence time estimates as minimum estimates.

We developed a candidate model set (see Table S2 in the Supplement at www.int-res.com/articles/suppl/ n036p279_supp.pdf) to assess variation in residence patterns across time and to evaluate hypotheses for factors that may influence SEUS residence time by combining different models for each parameter type $\left(\right.$ pent $_{j}, \varphi_{j}{ }^{(v)}$, and $\left.p_{j}\right)$. We estimated parameters using maximum likelihood with Program MARK (v. 8.1; White \& Burnham 1999) via the RMark package (v. 2.1.13; Laake 2013) in R (R Core Team 2015). Model selection was based on Akaike's Information Criterion corrected for small sample sizes (AICc), and parameter estimates were averaged based on AICC weights $\left(w_{i}\right)$ to account for model selection uncertainty (Burnham \& Anderson 2002). AICc was calculated based on unadjusted parameter counts rather than the numerically derived number of estimable parameters (Laake 2013). Currently, there is no general goodness-of-fit (GOF) test for the MSORD model so we evaluated fit for fully time-dependent Cormack Jolly Seber models run individually for each season (Lebreton et al. 1992). We did not consider demographic group differences here due to limited data. Cumulative $\chi^{2}$ statistics and degrees of freedom for Test $2+$ Test 3 were obtained from Program RELEASE GOF implemented in Program MARK (v. 8.1; White \& Burnham 1999). These tests assess violation of model assumptions due to heterogeneity in capture probability (Test 2) and survival (Test 3) where, for our study, survival is interpreted as remaining in the study area.

\section{Covariates for within-season parameters}

The phenology of migration is likely influenced by factors that are either group-specific, environmental, or interactions between these factors (Knudsen et al. 2007). For right whales, we evaluated differences in arrival $\left(p e n t_{j}\right)$, persistence $\left(\varphi_{j}^{(v)}\right)$, and sighting probabilities $\left(p_{j}\right)$ as a function of seasons, biweeks within each season, and demographic groups, and we modeled relationships of parameters with environmental covariates representing sea surface temperature (SST), primary production, and climatic conditions. Seasonal variation was evaluated using a factor variable (SEASON) to group capture histories of individuals that were observed in each season. To quantify time dependence in arrival and persistence parameters, we evaluated models with time effects that either varied across all biweeks ( Time) or that had linear or quadratic relationships (on the logit scale) for biweeks with either a multiplicative ( SEASON $\times$ QUAD) or additive ( SEASON + QUAD) seasonal effect. The linear and quadratic models were used to characterize temporal trends in arrival and persistence within a season while requiring fewer parameters than a fully time-dependent model. We also considered an effect of survey effort (Caswell et al. 1999, Fujiwara \& Caswell 2001) on $p_{j}$. We summarized EFFORT as kilometers flown in the SEUS study area within each biweek standardized relative to the mean biweekly effort across the study period. We ignored the small contribution of non-aerial sightings to effort, due to the absence of comparable effort data.

\section{Demographic factors}

We expected differences in arrival and persistence probabilities among age, sex, and reproductive classes due to different life history and energy requirements (Clapham 2001, Craig et al. 2003, Fortune et al. 2013) and expected different sighting probabilities across demographic groups due to differences in surface-to-dive time ratios or calf presence (Hain et al. 1999, Fewster \& Patenaude 2009). We therefore evaluated differences across the 5 demographic groups for all parameters by comparing models with and without a demographic group factor variable 
(DG). Additionally, we tested the hypothesis that calving female persistence is a function of the time since arrival in the SEUS (i.e. the number of biweeks since arrival; $\sim$ Cow:TSA), which may relate to a minimum amount of time needed for a calf to develop prior to migrating north (e.g. developing sufficient swimming skills; NMFS 2014). Differences across demographic groups were also evaluated for interactions with environmental covariates.

\section{Environmental factors}

Environmental covariates were summarized within a subset of 4 regions among the SEUS and northeast US and Canadian Maritimes (NEUS) coasts. Environmental conditions in the SEUS (prior to northward migration) were only considered relative to persistence probabilities, and conditions in the NEUS (prior to southward migration) were only considered relative to arrival probabilities. Regions in the NEUS were defined based on historically high-use right whale habitats that were simplified by aggregating adjacent areas into either the NEUS-A (Bay of Fundy, Gulf of Maine, Grand Manan Banks, Jeffrey's Ledge, Cape Cod Bay, and Massachusetts's Bay) or NEUS-B (East Scotian Shelf and Roseway Basin) regions
(Schick et al. 2013; Fig. 1). Aggregation was based on similarities in observed SST during the study period. We also considered the entire NEUS region by combining the NEUS-A and NEUS-B regions. The SEUS region was defined as the North Carolina/South Carolina border south to Jupiter, FL, with an offshore extent out to the approximate location of the midcontinental shelf (Fig. 1). This extent encompasses historical right whale sightings in the SEUS region since 1991 (Gowan \& Ortega-Ortiz 2014).

Sea surface temperature. Variation in right whale distribution has been linked to SST (Keller et al. 2006, Pendleton et al. 2012), and right whales may have an upper thermal limit (Kenney 2007, Good 2008), while cow-calf pairs may avoid particularly cold water (Keller et al. 2006). Since SEUS shelf waters typically cool rapidly between September and October (Blanton et al. 2003), we quantified the timing of seasonal cooling for the corresponding period in the NEUS using SST anomalies calculated as the difference between October SST in the NEUS-A or NEUS-B regions and mean October SST across the study period in each region (Covariates 1 and 2; Table 1). We expected earlier arrival in years with below-average October SST. We also expected earlier arrival when NEUS winter SST was colder than average (Covariate 3 ; Table 1). Conversely, we pre-

Table 1. Definitions of environmental covariates (SST: sea surface temperature; CHL: chlorophyll $a$; NAO: the North Atlantic Oscillation index) evaluated for the arrival and persistence parameters of the multistate open robust design model. See Fig. 1 for region locations in the northeastern United States and Canadian Maritimes coasts (NEUS) and the southeastern United States (SEUS)

\begin{tabular}{|c|c|c|}
\hline Parameter & Covariate & Description \\
\hline \multicolumn{3}{|l|}{ Arrival } \\
\hline 1 & SSTAnom ${ }_{\text {Oct,NEUS-A }}$ & $\begin{array}{l}\text { Anomaly of mean NEUS-A October SST relative to mean October NEUS-A SST } \\
\text { across all seasons }\end{array}$ \\
\hline 2 & SSTAnom $_{\text {Oct,NEUS-B }}$ & $\begin{array}{l}\text { Anomaly of mean NEUS-B October SST relative to mean October NEUS-B SST } \\
\text { across all seasons }\end{array}$ \\
\hline 3 & SSTAnom $_{\text {Winter,NEUS }}$ & $\begin{array}{l}\text { Anomaly of mean December-February NEUS SST relative to mean winter NEUS } \\
\text { SST across all seasons }\end{array}$ \\
\hline 4 & CHLAnom $_{\text {Spring,NEUS }}$ & $\begin{array}{l}\text { Anomaly of mean March-April NEUS CHL relative to mean spring NEUS CHL } \\
\text { across all seasons }\end{array}$ \\
\hline 5 & CHLAnom $_{\text {Summer,NEUS }}$ & $\begin{array}{l}\text { Anomaly of mean May-July NEUS CHL relative to mean summer NEUS CHL } \\
\text { across all seasons }\end{array}$ \\
\hline 6 & CHLAnom $_{\text {Fall,NEUS }}$ & $\begin{array}{l}\text { Anomaly of mean August-November NEUS CHL relative to mean fall NEUS CHL } \\
\text { across all seasons }\end{array}$ \\
\hline 7 & $\mathrm{NAO}$ & Mean North Atlantic Oscillation index values for October to April of each season \\
\hline \multicolumn{3}{|l|}{ Persistence } \\
\hline 8 & $\mathrm{SST}_{\mathrm{SEUS}}$ & Mean SEUS SST in degrees Celsius for each biweek \\
\hline 9 & SSTSlope $_{\text {SEUS }}$ & Rate of change in SEUS biweekly mean SST from the previous biweek \\
\hline 10 & $\mathrm{SST}_{\text {Winter,SEUS }}$ & Mean SEUS SST in degrees Celsius from December to February for each season \\
\hline 11 & SSTAnom $_{\text {Winter,SEUS }}$ & $\begin{array}{l}\text { Anomaly of mean December-February SEUS SST relative to mean winter SEUS } \\
\text { SST across all seasons }\end{array}$ \\
\hline 12 & NAO & Mean North Atlantic Oscillation index values for October to April of each season \\
\hline
\end{tabular}


dicted departure timing to be influenced by warming SEUS SST and expected persistence probabilities to decrease (1) with increasing biweekly mean SEUS $\mathrm{SST}_{i}(2)$ after the rate of change in biweekly SEUS SST values became positive; or (3) earlier in the season (i.e. earlier departure) when SEUS winter mean SST values for each season and SEUS winter SST anomalies were above the study period mean winter SEUS SST (Covariates 8 to 11, respectively; Table 1).

SST covariates were derived from global daily mean SST $\left({ }^{\circ} \mathrm{C}\right)$ data for October 2004 to April 2011 obtained from the NOAA OI SST V2 high resolution blended data set (Reynolds et al. 2007) provided online by the NOAA Earth System Research Laboratory Physical Sciences Division (www.esrl.noaa.gov/ psd/). Daily mean SST data were used as a bulk measure of regional temperature and were summarized into biweekly, October, and seasonal means and anomalies across the study period (Table 1).

Primary production. Given the energetic demands of long-distance migration and fasting within SEUS wintering grounds (Kenney et al. 1986, Fortune et al. 2013), we expected arrival timing to be related to the quality, abundance, and phenology of food resources available to right whales prior to migration. Abundance and phenology of Calanus finmarchicus, the primary prey for right whales (Baumgartner et al. 2003), are influenced by oceanographic processes and large-scale climatic fluctuations, such as the North Atlantic Oscillation (Drinkwater et al. 2003, Greene \& Pershing 2003) as well as the magnitude, timing, and duration of phytoplankton blooms (Durbin et al. 2003, MERCINA 2004, Johnson et al. 2008).

We evaluated effects of phytoplankton bloom magnitude and timing prior to the winter season on arrival probabilities across seasons using satellitederived surface chlorophyll a concentrations in $\mathrm{mg}$ $\mathrm{m}^{-3}$ (CHL) as an indicator of primary production (Song et al. 2010). Seasonal NEUS CHL anomalies were calculated relative to study period seasonal means (Covariates 4-6 in Table 1) from 2004 to 2010, with seasons defined according to climatological seasonal cycles observed for $C$. finmarchicus (Spring: March-April, Summer: May-July, Fall: August-November; MERCINA 2004). Seasonal mean values were derived from monthly mean CHL data from SeaWiFS level-3, 1/12 degree resolution data for 2004-2010 obtained from the NASA Ocean Biology Processing Group (NASA 2014) using Marine Geospatial Ecology Tools v. 0.8a43 (Roberts et al. 2010) and summarized within the NEUS region with the Spatial Analyst Zonal Statistics tool in ArcGIS (ESRI 2014).
North Atlantic Oscillation Index. The North Atlantic Oscillation (NAO) is a coupled ocean-atmospheric system quantified using NAO index values that indicate the difference of pressure anomalies between the Azores and Iceland (Hurrell 1995). Most prominent during boreal winter, the NAO influences northern hemisphere climate, weather, and ecosystems, including plankton communities (Hurrell 1995, Drinkwater et al. 2003, Greene \& Pershing 2003). Negative winter NAO indices indicate a decreased pressure gradient and are generally associated with increased transport of cool, fresh Labrador Current water to south of the Grand Banks and lower C. finmarchicus abundance in the northwest Atlantic (Greene \& Pershing 2000, Conversi et al. 2001, Greene et al. 2013). Changes in oceanic conditions associated with NAO variability have been linked to ecological dynamics at multiple trophic levels (Ottersen et al. 2001), including C. finmarchicus abundance in the Gulf of Maine (Greene \& Pershing 2000) and right whale body condition (Miller et al. 2012) and calf production (Meyer-Gutbrod et al. 2015).

We calculated the winter NAO index from monthly mean NAO index values normalized to 1981-2010 monthly means obtained from the NOAA Climatic Prediction Center (www.cpc.ncep.noaa.gov/products/ precip/CWlink/pna/nao.shtml). Monthly mean NAO index values were averaged from October to April for each winter season (Covariates 7 and 12 in Table 1). We expected later arrival (i.e. peak arrival probabilities later in the season) during seasons with a negative NAO index, since whales may arrive later if more time is needed to accumulate sufficient energy stores before migrating or if whales disperse to alternative feeding grounds and then must travel farther to reach the SEUS (Meyer-Gutbrod et al. 2015). Alternatively, we expected higher persistence probabilities to extend later into the season (i.e. later departure) during negative NAO seasons because coastal waters within the SEUS would be expected to stay cooler longer than during a positive phase NAO season.

\section{RESULTS}

\section{Right whale sightings}

Of the records obtained from the Identification database, we analyzed 7601 photo-identified sighting records for 408 individual whales Eubalaena glacialis. Most records (86\%) were from EWS aerial surveys, with other sighting sources consisting of 
vessels $(10.3 \%)$, land-based sightings $(2.5 \%)$, and unspecified platforms (1.1\%). The 2009/2010 season had the most unique individuals (220), while 2008/ 2009 had the highest number of sightings $(1560$; see Fig. S1 in the Supplement). Except for 2004/2005 when adult males were most common, most identified individuals in each season were juveniles, and the proportion of juveniles increased across the study period (Table S1). Across all demographic groups, the average number of days between sightings was $5.3 \mathrm{~d}(\mathrm{SD}=6.6)$, but $7 \%$ of sighting gaps were longer than the biweekly secondary period. Where SEUS sighting gaps were $>14 \mathrm{~d}$, the Identification database (NARWC 2014) was further examined for movement out of the study area, but we found no photo-identified sightings of these whales in other locations to confirm the whales had left the SEUS during these gaps (P. Hamilton pers. comm.).

\section{Model results}

Of the models evaluated (Table S2), 6 models had some support ( $\left.w_{i}>0.001\right)$, and Model 1 had $90.7 \%$ of the AICc weight (Table 2). Cumulative goodness-offit results did not indicate a lack of fit $\left(\chi^{2}=134.34\right.$, df $=125, \mathrm{p}=0.268 ; \hat{\mathrm{c}}=1.07$ ). The models best supported by the data indicated differences among DGs for all parameters; differences in arrival (pent) and persistence $(\varphi)$ parameters across biweeks that were modeled with a quadratic time trend (QUAD); and biweekly sighting probabilities $(p)$ that were modeled with an interaction between demographic group and survey effort (DG $\times$ Effort). Four of the 6 supported models included 1 of 3 environmental anomaly covariates for arrival timing: NEUS-A October
SST, NEUS-B October SST, or NEUS fall CHL (Fig. S2). In contrast, top persistence models did not indicate support for the environmental covariates evaluated or for the time-since-arrival hypothesis for calving females. All top models included either additive or multiplicative seasonal effects on persistence, and models with an additive effect received the most support (cumulative $w_{i}=0.950$; Table 2). We used model averaging to account for model selection uncertainty and present averaged results for each parameter, noting that Model 1 had the most support.

Arrival probabilities indicated staggered arrival that varied across demographic groups and time (Fig. 2a-e). For each season, each biweekly arrival probability was $>0$ for at least 1 demographic group, indicating that right whales arrived throughout the winter. However, arrival patterns were distinct among demographic groups, with calving and noncalving adult females tending to arrive earliest, followed by juveniles, unknown age/sex individuals, and then adult males (Fig. 2a-e). Across seasons, some calving females and non-calving adult females arrived or were already present in the study area during the first biweek from 15 November to 28 November (first occasion pent values; Fig. 2a,b). In contrast, few juveniles were present in the first biweek (Fig. 2d), unknown age/sex individuals did not arrive until the second biweek except in 2006/2007 (Fig. 2e), and most adult males did not arrive until after late January (Fig. 2c). Juvenile whale arrival patterns were very consistent across seasons (Fig. 2d).

Similar to arrival probabilities, departure times were staggered, with variation across seasons and demographic groups. In all seasons, calving females stayed in the SEUS until at least mid-January, while other groups had lower persistence probabilities

Table 2. Top 6 multistate open robust design models of arrival (pent), persistence $(\varphi)$, and sighting probabilities $(p)$, with $>0.001$ $\mathrm{AIC}_{\mathrm{c}}$ weight $\left(w_{i}\right)$ where $\mathrm{AIC}_{\mathrm{c}}$ is Akaike's information criterion corrected for small sample sizes, $K$ is the total number of parameters in each model, and $\triangle \mathrm{AIC}_{\mathrm{C}}$ is the difference in $\mathrm{AIC}_{\mathrm{C}}$ values from model [1]. Variation in linear and quadratic relationships for secondary periods across seasons is indicated by the QUAD term. Factor variables were demographic group (DG) and the primary period winter seasons (SEASON), while covariate values were October sea surface temperature anomalies for the NEUS-A (SSTAnom Oct,NEUS-A $)$ and NEUS-B (SSTAnom $_{\text {Oct,NEUS-B }}$ ) regions; surface chlorophyll $a$ anomalies for August to November in the NEUS region $\left(\right.$ CHLAnom Fall,NEUS $_{\text {); }}$ and standardized biweekly aerial survey effort (EFFORT). See Table S2 in the Supplement at www.int-res.com/articles/suppl/n036p279_supp.pdf for full $\mathrm{AIC}_{\mathrm{c}}$ table

\begin{tabular}{|c|c|c|c|c|c|}
\hline & Model & $K$ & $\Delta \mathrm{AIC}_{\mathrm{c}}$ & $w_{i}$ & Deviance \\
\hline 1 & pent $\left(\mathrm{DG} \times \mathrm{QUAD} \times \mathrm{SSTAnom}_{\mathrm{Oct}, \mathrm{NEUS}-\mathrm{A}}\right), \varphi(\mathrm{QUAD} \times \mathrm{DG}+\mathrm{SEASON}), p(\mathrm{DG} \times \mathrm{EFFORT})$ & 61 & 0.000 & 0.907 & 8039.49 \\
\hline 2 & pent $\left(\mathrm{DG} \times \mathrm{QUAD} \times \mathrm{SSTAnom}_{\mathrm{Oct}, \mathrm{NEUS}-\mathrm{A}}\right), \varphi(\mathrm{QUAD} \times \mathrm{DG} \times \mathrm{SEASON}), p(\mathrm{DG} \times \mathrm{EFFORT})$ & 145 & 5.863 & 0.048 & 7864.27 \\
\hline 3 & pent $(\mathrm{DG} \times \mathrm{QUAD}), \varphi(\mathrm{QUAD} \times \mathrm{DG}+\mathrm{SEASON}), p(\mathrm{DG} \times \mathrm{EFFORT})$ & 46 & 6.814 & 0.030 & 8077.49 \\
\hline 4 & pent $(\mathrm{DG} \times \mathrm{QUAD} \times \mathrm{SSTAnom}$ Oct,NEUS-B $), \varphi(\mathrm{QUAD}+\mathrm{SEASON} \times \mathrm{DG}), p(\mathrm{DG} \times \mathrm{EFFORT})$ & 61 & 8.971 & 0.010 & 8048.46 \\
\hline 5 & pent $\left(\mathrm{DG} \times \mathrm{QUAD} \times \mathrm{CHLAnom}_{\mathrm{Fall}, \mathrm{NEUS}}\right), \varphi(\mathrm{QUAD} \times \mathrm{DG}+\mathrm{SEASON}), p(\mathrm{DG} \times \mathrm{EFFORT})$ & 61 & 11.549 & 0.003 & 8051.04 \\
\hline 6 & pent $(\mathrm{DG} \times \mathrm{QUAD}), \varphi(\mathrm{QUAD} \times \mathrm{DG} \times \mathrm{SEASON}), p(\mathrm{DG} \times \mathrm{EFFORT})$ & 130 & 14.035 & 0.001 & 7905.61 \\
\hline
\end{tabular}



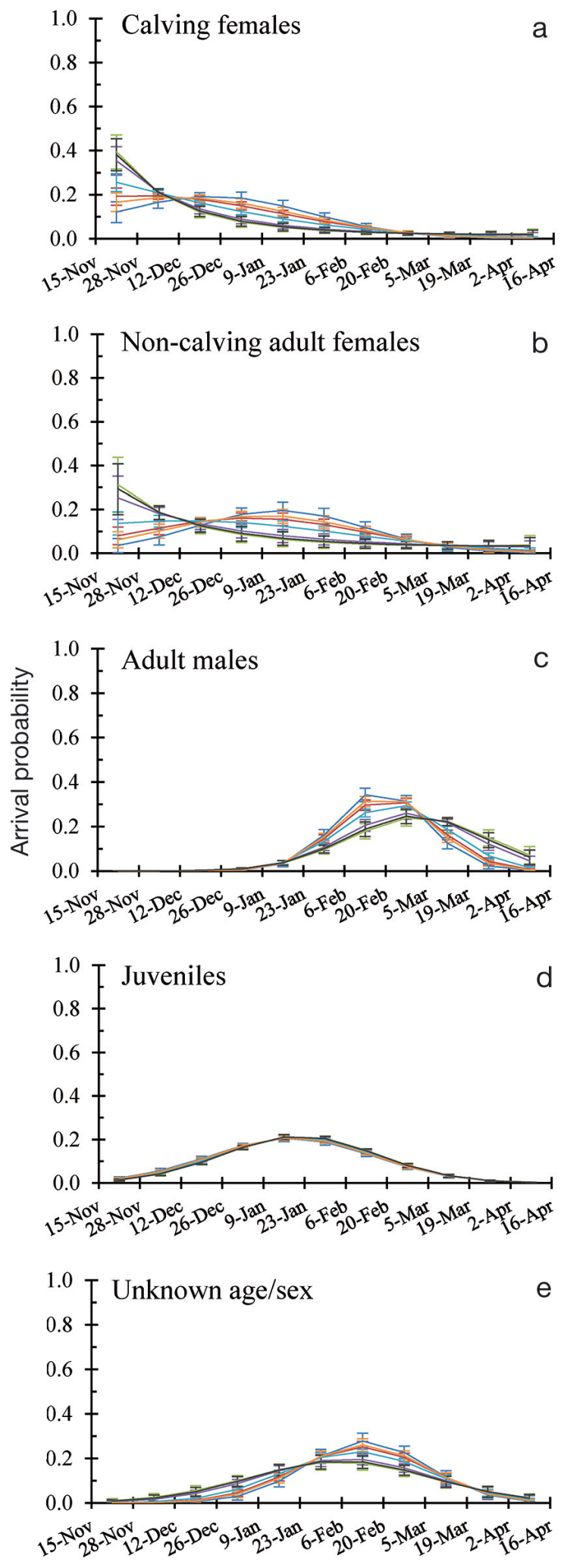

Biweek
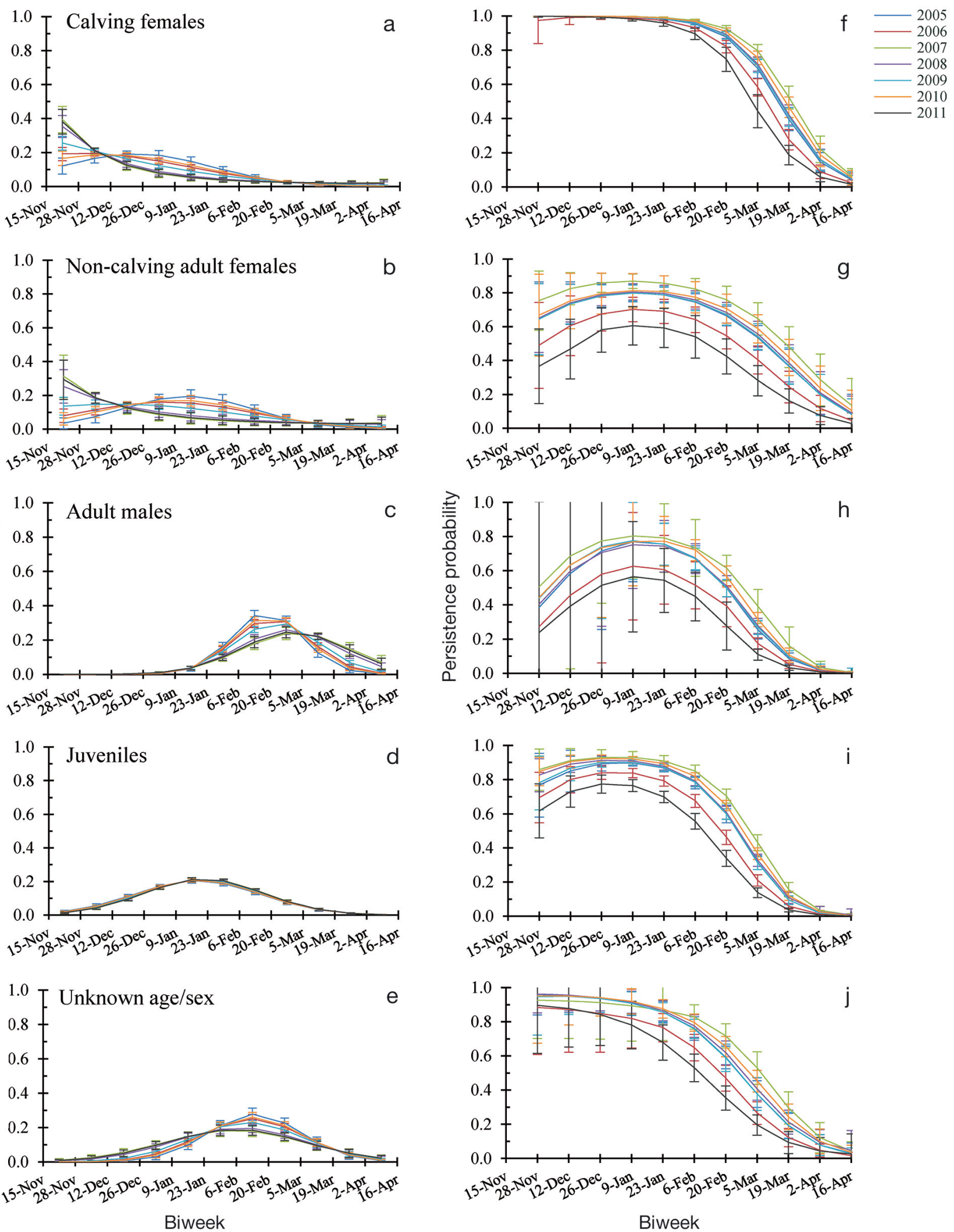

Fig. 2. Model-averaged parameter estimates for biweekly probabilities of (a-e) arrival (pent) and (f-j) persistence $(\varphi)$ for each season for $(\mathrm{a}, \mathrm{f})$ calving females, $(\mathrm{b}, \mathrm{g})$ non-calving adult females, $(\mathrm{c}, \mathrm{h})$ adult males, $(\mathrm{d}, \mathrm{i})$ juveniles, and $(\mathrm{e}, \mathrm{j})$ unknown age/sex individuals. Error bars indicate SE 
overall (Fig. 2). In fact, calving female persistence probabilities were $>0.50$ through at least Biweek 7 (7-20 February) for all seasons, indicating that these individuals were more likely to stay in the study area than to leave (Fig. 2f). Similar patterns were observed for noncalving adult females, except in 2005/ 2006, 2006/2007, and 2010/2011. For juveniles and unknown age/sex individuals, 7 of 11 biweeks had persistence probabilities $>0.50$ in most seasons; persistence probabilities were lower for these groups in 2005/2006 and 2010/2011 and higher in 2006/2007 (Fig. 2i,j). In contrast, adult males were more likely to leave than to stay during the majority of biweeks in each season except for 2006/2007, 2007/2008, and 2009/2010 (Fig. 2h). We note the large uncertainty associated with persistence estimates for adult males for the first 3 biweeks; this is because persistence is conditional on prior arrival, and male arrival probabilities were near zero for these biweeks. Adult males were the only demographic group for which persistence probabilities decreased to zero in all seasons, with this occurring during Biweek 11 (3-16 April). Across demographic groups, 2005/2006 and 2010/2011 had the lowest overall persistence probabilities, and persistence probabilities were highest during 2006/2007 (Fig. 2f-j).

Differences in arrival and persistence probabilities across seasons and groups were reflected in variation in residence patterns. In most seasons, calving females stayed in the SEUS more than twice as long as individuals in other groups, with an overall mean residence time ( \pm 1 average SE) of $87.5 \pm 4.9$ d (range: 78.9 - $99.6 \mathrm{~d}$; Table 3). Adult males consistently had the shortest residence times with an overall mean of $20.4 \pm 1.1 \mathrm{~d}$ (range: $16.8-22.8 \mathrm{~d}$; Table 3 ). Mean residence times for non-calving adult females and juveniles were similar in all seasons (Table 3). Within demographic groups, estimated mean residence times were shortest in 2010/2011 (except for calving females and unknown age/sex individuals, which were shortest in 2005/2006) and longest in 2006/2007 (except for adult males, which were longest in 2009/2010).

Demographic and seasonal differences were also indicated in estimates of $p_{j}$ (i.e. biweekly sighting probabilities); however, overall patterns generally followed patterns in biweekly aerial survey effort (Fig. S3). Survey effort and detection probabilities were lower during the first and last biweeks, due in part to variable timing in survey start and end dates across seasons. In all seasons, calving females had the highest seasonal detection rates $\left(p^{*}\right)$, followed by juveniles, adult males, unknown age/sex individuals, and non-calving adult females (Table 4). However, $p^{*}$ values decreased for all demographic groups during the 2010/2011 season, which had $21 \%$ less effort than the study period average (Fig. S3 in the Supplement). Seasonal abundance estimates indicated that there were more juveniles, adult males, and unknown age/sex individuals in the SEUS than observed (Fig. 2).

\section{DISCUSSION}

Although right whale Eubalaena glacialis distribution and movement patterns have been described (Winn et al. 1986, Schick et al. 2013), temporal components of right whale distribution, including residence time in high-use areas, are less well understood. The generally accepted North Atlantic right whale seasonal migration model consists of south- 
ward movement during fall or early winter and northward movement during late winter or spring (Kraus et al. 1986, Winn et al. 1986, Firestone et al. 2008). However, we observed staggered arrival and departure patterns that are not consistent with this model. Instead of a distinct peak in arrival probabilities early in the season, our models indicated arrivals for at least one demographic group in all biweeks of the winter. Furthermore, instead of a sharp decline in persistence probabilities at the end of the season, we observed persistence probabilities below 0.50 as early as Biweek 6 (24 January to 6 February), which indicates that some right whales likely leave the SEUS in the middle of the winter season. Our capturerecapture modeling framework results described variation in SEUS wintering ground residence patterns among demographic groups, identified potential influences for variation across time, and provided estimates of winter abundance in the SEUS study area, which can inform monitoring and management actions to support right whale recovery.

\section{Demographic factors}

We observed distinct residence patterns among demographic groups, which supports our hypothesis that life history and behavioral differences influence right whale residence timing in the SEUS. Demographic differences were more apparent in arrival patterns than in persistence, with calving and noncalving adult females arriving earlier than other groups (Fig. 2a-e). Our estimates of right whale arrival patterns for the SEUS area are consistent with arrival patterns for males and females described by Schick et al. (2013), although that work did not consider differences due to age class or calving status. Earlier arrival by calving females contributed to calving females having the longest mean ( \pm 1 average $\mathrm{SE}$ ) residence time of any demographic group (87.5 \pm $4.9 \mathrm{~d}$; Table 3). Fortune et al. (2013) also described longer SEUS residence periods for calving females $(46.32 \pm 14.60 \mathrm{~d})$ than for non-lactating females $(23.75$ $\pm 18.6 \mathrm{~d})$, juveniles $(16.33 \pm 8.50 \mathrm{~d})$, or adult males $(3.11 \pm 3.33 \mathrm{~d})$ using first and last sighting dates in the SEUS from 1991 to 2009 (estimates from Fortune et al. 2013 are means \pm SD). Longer mean residence periods have also been documented for Southern right whale Eubalaena australis calving females relative to other demographic groups at wintering grounds in Península Valdés, Argentina (calving females mean $=77 d_{i}$ other groups mean $=52 d_{i}$ Rowntree et al. 2001) and southern Australia (calving fe- males mean $=70.9 \mathrm{~d}$; whales without calf mean $=$ 20.4 d; Burnell \& Bryden 1997). Our mean residence time estimates are longer than estimates for these Southern right whale wintering grounds and much longer than previous estimates by Fortune et al. (2013). This disparity may reflect real differences across time, populations, or habitats; however, direct comparison may not be appropriate since these other studies did not account for imperfect detection, which could result in underestimates of residence duration. Furthermore, our calving female residence time estimates should be considered a minimum residence period since calving females have occasionally been sighted in the SEUS before aerial surveys begin (NARWC 2014) and may stay after aerial surveys end (last occasion $\varphi$ values $>0$; Fig. 2f). This interpretation may not apply to adult males if they only enter and exit the SEUS once, since adult male arrival and departure was fully encompassed by the timing of dedicated aerial surveys. Underestimating residence time by not accounting for imperfect detection or survey effort influences can lead to incorrect inferences. For example, our longer residence duration estimates suggest the physiological implications of fasting in the SEUS wintering grounds predicted by Fortune et al. (2013) may be underestimated.

The SEUS residence patterns described by our study are more typical of differential migration than the generally accepted North Atlantic right whale migration model. Differential migration is characterized by variable migration timing among individuals in different age, sex, and reproductive classes and has been observed in other baleen whale species, including Antarctic blue whales (Thomisch et al. 2016) and humpback whales (Craig et al. 2003, Stevick et al. 2003). Possible reasons for a differential migration strategy for right whales include the influence of feeding ground location on migration timing and the impacts of migration timing on body condition and fitness. For example, adult females may require different prey types at different times of their reproductive cycle and exhibit flexibility in their use of spring, summer, and fall feeding habitats (Brown et al. 2001). In turn, flexibility in feeding ground location may result in variable arrival and departure timing due to the difference in time required to migrate to and from the SEUS from different locations (Stevick et al. 2003). Additionally, early arrival and longer residence times by calving females may increase calf fitness by allowing calves more time to develop in the supportive conditions of the SEUS habitat prior to migration to higher-latitude habitats (Clapham 2001). Although a time-since-arrival co- 
variate was not supported in our top models for calving female persistence (Table 2), this was not surprising since arrival does not necessarily coincide with calf birth (Kraus et al. 1986) and cow-calf associations can last longer than one winter season (Hamilton \& Cooper 2010). Estimates of calf survival will be required to compare the fitness of calves of earlyarriving females to calves of later-arriving females, while also accounting for calf age. Furthermore, departure timing patterns across demographic groups were more similar than arrival timing patterns across demographic groups, which may be due to whales leaving the SEUS to take advantage of NEUS food resources that occur at a predictable time in late winter or early spring. In particular, the end date of Calanus finmarchicus seasonal dormancy (approximately late January through late February) is more consistent than when it begins (Melle et al. 2014). Potential impacts of climate change, including warmer deep-water temperatures in the Gulf of Maine, could shift food resource phenology, causing C. finmarchicus to end dormancy earlier and resulting in shorter residence of right whales in the SEUS (Melle et al. 2014, Thomisch et al. 2016).

For demographic groups other than calving females, whose motivation for migration is unclear (Corkeron \& Connor 1999), observed arrival timing patterns are likely influenced by social factors, lifehistory related differences in energetic needs, and distributions prior to migration (Corkeron \& Connor 1999, Clapham 2001). For example, Murison \& Gaskin (1989) proposed that migrating to fast in warmer, lowlatitude waters may be more beneficial than competing for potentially limited food resources in colder, high-latitude waters throughout the year. Our observations of peak adult male arrival during February corresponding with the coldest SST in our NEUS summary area during February and March are consistent with this theory. Social considerations may be important for juveniles, who lack historical knowledge about temporally or spatially variable aspects of the seasonal migration (Hamilton \& Cooper 2010). Shaw \& Couzin (2013) also theorized that individuals without knowledge of resource conditions would rely on social sources to inform migration, including pooling individual knowledge of conditions through social interactions. Consistent with this theory, we observed juvenile arrival patterns that were similar over all seasons and overlapped with those of other demographic groups (Fig. 2a-e), which may reflect reliance on social interactions for migrating juvenile whales.

For unknown age/sex individuals, arrival patterns were similar to those of juveniles and adult males
(Fig. 2c-e). This is not unexpected since juveniles and adult males may be harder to age or sex due to lack of calving identifiers. Interestingly, calving and non-calving females had similar arrival patterns, which may reflect some uncertainty in the assignment of calving status. Although we expected low uncertainty for the calving female state assignment due to the intensive survey effort and survey conditions in the SEUS, some calving females may have been misclassified as non-calving females due to terminated pregnancies, undetected calf mortality, or departure from the SEUS before a calf was detected (Browning et al. 2010). If present, this misclassification would result in non-calving female residence time estimates being biased towards that of calving females while abundance estimates of non-calving females and calving females would be overestimated and underestimated, respectively. In future work, model frameworks that account for state uncertainty (Kendall 2004, Pradel 2005) could potentially use observed patterns in residence or other behaviors to inform the assignment of age, sex, or reproductive state for some unknown age/sex individuals or to account for potential misclassification of calving status.

\section{Environmental factors}

Demographic group influences on arrival time varied with changes in environmental factors across seasons. For instance, arrival patterns among seasons differed with NEUS October SST anomalies, although this relationship was different between adult males and all other demographic groups. Calving females, non-calving adult females, and unknown age/sex individuals arrived later, while adult males tended to arrive earlier, during seasons with belowaverage October NEUS-A SST (2004/2005, 2005/ 2006, and 2009/2010; see Fig. S2 in the Supplement). In seasons where October NEUS-A SST was above average (2006/2007, 2007/2008, 2010/2011; Fig. S2), arrival timing for these groups was earlier and later, respectively. This may indicate differences in thermal tolerance or energetic budgets across demographic groups or that whales respond to another, unknown environmental cue that is correlated with NEUS October SST.

In contrast to arrival, none of the environmental covariates evaluated for persistence had support in our top models; however, support for the seasonal effect suggests that temporal variability in some unidentified environmental condition influences departure timing from the SEUS. The lack of support 
for models with persistence SEUS SST covariates was unexpected given the importance of SST in SEUS habitat models (Gowan \& Ortega-Ortiz 2014). Within-season weather variability that influences SEUS SST may have masked the relationship between the SST covariates considered and variation in persistence among seasons. For example, 2010/2011 had the lowest persistence probabilities overall and the warmest SEUS biweekly temperatures for the last biweek, which agrees with our prediction that warmer SEUS biweekly SST at the end of the season would be associated with earlier departure. However, 2010/2011 also had the coldest SEUS December SST of the seasons considered and this variability likely contributed to the relative lack of support for SST covariates for persistence in the top models. Future work should account for such within-season variability when evaluating relationships with environmental covariates.

The NAO index was not a useful predictor of arrival or persistence in our models. The duration of our study may have been insufficient to detect effects of the NAO, which operates at a decadal scale (Greene \& Pershing 2000). In fact, 2007/2008 was the only winter in our study that had a positive winter index. We also did not consider lagged or cumulative effects that might be more relevant to right whale condition and behavior (Meyer-Gutbrod et al. 2015). Furthermore, the spatial or temporal scale used to summarize environmental data may not match the scale relevant to right whales. In addition to considering other environmental or biological variables such as right whale health (Rolland et al. 2016), future work should evaluate summarizing the variables we considered at different scales and incorporate information from large-scale oceanographic and physical-biological models (Pendleton et al. 2012).

\section{Management implications}

Beyond insights into right whale life history, our results can inform temporal components of monitoring, management, and conservation actions along the Atlantic coast. Current protection measures for right whales are determined based on the generally accepted migration model. However, our results show that this model is incomplete and that inferences should not be determined based on residence patterns averaged across demographic groups. For instance, Hiby \& Leaper (2005) predicted later modal departure dates in years with more calves present. This suggests that the presence of calves influences the residence time of all whales, whereas our results indicate that the later departure timing in seasons with more calves was due to the presence of more calving females, which had much longer residence periods than other groups. Also, variable residence patterns and phenology may result in different risk exposure among demographic groups if current protections do not provide spatial or temporal coverage for all individuals. For example, with the longest residence times and potential to arrive in the SEUS prior to the start of dedicated surveys, calving females that are critical to population growth (Fujiwara \& Caswell 2001) may have increased exposure to threats in the SEUS or while in transit along the mid-Atlantic coast if regulations do not account for the different residence patterns among demographic groups.

In addition to clarifying residence timing and duration in the SEUS, our results support the potential for right whale occurrence outside of known, high-use areas. Specifically, staggered arrival and persistence patterns suggest that whales may occur along the mid-Atlantic coast throughout the winter. This is consistent with observations from acoustic monitoring efforts that have documented winter acoustic presence of right whales along North Carolina and Georgia during all seasons without the bi-modal occurrence pattern that would be expected if southward and northward migrations occurred collectively (Hodge et al. 2015). Another acoustic study detected right whale presence off Virginia with peaks in detections during October to December and February to March (Salisbury et al. 2016). Although these peaks align with the expected southward and northward migration periods, the spring peak was larger than the fall peak. Our results suggest that the smaller fall peak could be explained by the higher variability in arrival dates across demographic groups compared to departure in the spring, or that the larger spring peak might include southward movement of late-arriving migrating individuals such as adult males. However, these explanations cannot be fully evaluated since Salisbury et al. (2016) did not identify individual animals. Our results, together with observations from other work, provide additional evidence that SEUS winter residence and migratory corridor use are more dynamic than previously thought. The residence timing estimates provided by our study could provide preliminary information to plan more detailed surveys of the presumed migratory corridor.

Aerial surveys are an important tool for monitoring right whale population status, habitat use, and the effectiveness of management actions. Our models highlighted the close relationship between aerial sur- 
vey effort and right whale detection probabilities in the SEUS. Survey effort should therefore be allocated to meet desired conservation and management objectives. For example, if identifying calving females to estimate their survival and reproductive rates (Fujiwara \& Caswell 2001) or mitigating their ship strike risk (e.g. Keller et al. 2006, Martin et al. 2016) are primary goals, survey effort levels observed across the study period were very effective (mean $p^{*}=0.98 \pm$ $0.02 \mathrm{SE}$ ) at sighting these individuals even when reduced effort in 2010/ 2011 decreased $p^{*}$ to $0.94 \pm 0.04 \mathrm{SE}$. This effectiveness is likely due to the typically long residence periods of calving females in the area, which make calving females more available

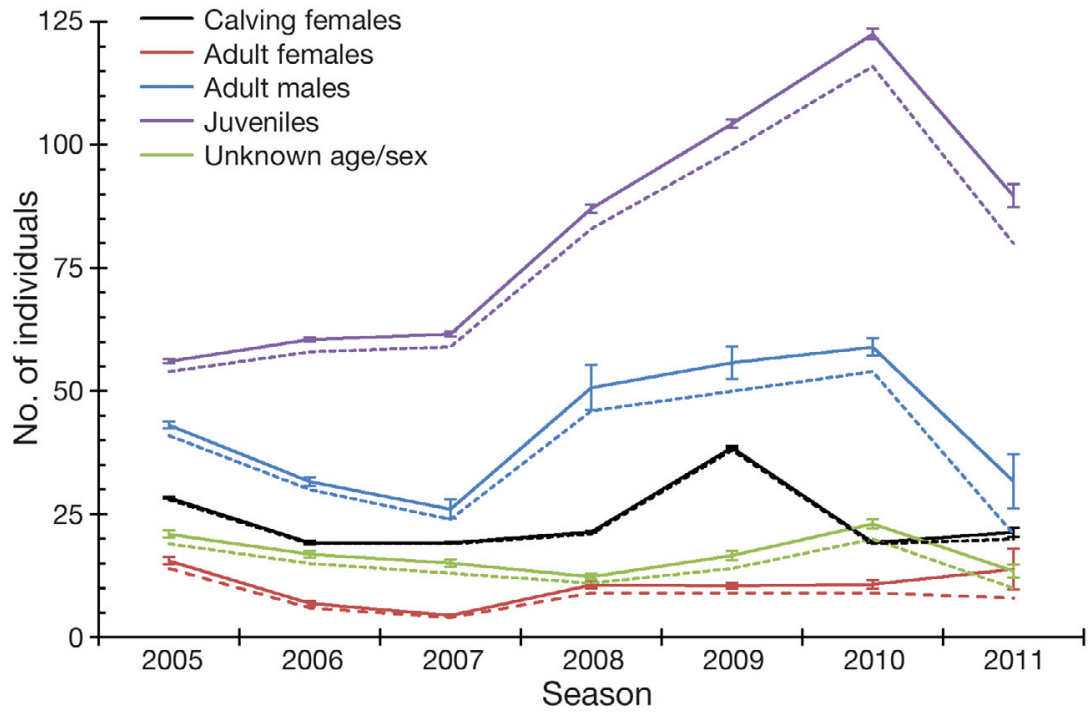

Fig. 3. Estimated abundances (solid lines with error bars indicating SE) and observed counts (dashed lines) of identified whales in the SEUS study period for each demographic group and season to be sighted at least once in a given season. In contrast, $p^{*}$ values for individuals in other groups were more negatively impacted by the decrease in survey effort in the last season of our study period, possibly due to their shorter residence times. Detection rates could be further reduced if the timing of residency coincides with poor survey conditions. For instance, survey effort decreased in Biweeks 5 or 6 in most seasons during the short window when adult males were present, and this decrease may be related to poor weather conditions that can impact the ability to fly surveys in the SEUS during late January and early February.

In addition to informing monitoring efforts, detection probabilities can also be used to adjust abundance estimates from observed counts. Here, we provided the first estimates that account for imperfect detection of the number of whales in each demographic group that used the study area each winter (Fig. 3). These abundance estimates could be used to make better predictions about risk of mortalities associated with major threats (e.g. ship strikes, see Martin et al. 2016), for example. We recommend that future population assessments consider the effects of survey effort and variable residency on right whale detection probabilities.

The modeling approach presented in this study provides information about the temporal distribution and phenology of mobile or migratory species where mark-recapture-type data are available and could be applied to other species or other right whale aggregation areas. For right whales, our within-season models can also be used to inform a more comprehensive cap- ture-recapture modeling analysis using the full MSORD model to estimate survival, state transitions, and temporary emigration dynamics. Our work contributes to a more complete understanding of right whale phenology and duration in the SEUS. Understanding where and when whales occur is critical for planning spatially and temporally dynamic conservation, research, and monitoring efforts; evaluating habitat use; and completing risk assessment analyses to reduce deaths and serious injuries from ship strikes and fishing gear entanglements, which impede the recovery of this highly endangered species.

Acknowledgements. We thank the North Atlantic Right Whale Consortium and its members for access to right whale sighting and photo identification data, the right whale photo-identification survey observers, and all who have contributed data to and curated the Sightings and Identification databases. Thank you to J. Hostetler, H. Edwards, and L. Ward, FWRI, for valuable discussions about the study; D. Pendleton, New England Aquarium, and K. B. Langtimm, USGS, for feedback on the manuscript; and P. Hamilton, New England Aquarium, for performing additional database queries for our data access request. Funding for the data analyses was provided by NOAA Fisheries and the State of Florida Save the Manatee Trust Fund. Any use of trade, firm, or product names is for descriptive purposes only and does not imply endorsement by the US Government.

\section{LITERATURE CITED}

Baumgartner MF, Cole TVN, Campbell RG, Teegarden GJ, Durbin EG (2003) Associations between North Atlantic right whales and their prey, Calanus finmarchicus, over diel and tidal time scales. Mar Ecol Prog Ser 264:155-166 
Blanton BO, Aretxabaleta A, Werner FE, Seim HE (2003) Monthly climatology of the continental shelf waters of the South Atlantic Bight. J Geophys Res 108:1-42

Bowlin MS, Bisson IA, Shamoun-Baranes J, Reichard JD and others (2010) Grand challenges in migration biology. Integr Comp Biol 50:261-279

Brown MW, Kraus SD, Gaskin DE, White BN (1994) Sexual composition and analysis of reproductive females in the North Atlantic right whale, Eubalaena glacialis, population. Mar Mamm Sci 10:253-265

Brown MW, Brault S, Hamilton PK, Kenney RD and others (2001) Sighting heterogeneity of right whales in the western North Atlantic: 1980-1992. J Cetacean Res Manag Spec Issue 2:245-250

Brown MW, Kraus SC, Slay CK, Garrison LP (2007) Surveying for discovery, science, and management. In: Kraus SD, Rolland RM (eds) The urban whale: North Atlantic right whales at the crossroads. Harvard University Press, Cambridge, MA, p 105-137

Brown MW, Fenton D, Smedbol K, Merriman C, RobichaudLeBlanc K, Conway J (2009) Recovery strategy for the North Atlantic right whale (Eubalaena glacialis) in Atlantic Canadian waters. Species at Risk Act Recovery Strategy Series. Fisheries and Oceans Canada, Ottawa

Browning CL, Rolland RM, Kraus SD (2010) Estimated calf and perinatal mortality in western North Atlantic right whales (Eubalaena glacialis). Mar Mamm Sci 26:648-662

Bunnefeld N, Börger L, van Moorter B, Rolandsen CM, Dettki H, Solberg EJ, Ericsson G (2011) A model-driven approach to quantify migration patterns: individual, regional and yearly differences. J Anim Ecol 80:466-476

Burnell SR, Bryden MM (1997) Coastal residence periods and reproductive timing in southern right whales, Eubalaena australis. J Zool 241:613-621

Burnham KP, Anderson DR (2002) Model selection and inference: a practical information-theoretic approach. Springer-Verlag, New York, NY

Caswell H, Fujiwara M, Brault S (1999) Declining survival probability threatens the North Atlantic right whale. Proc Natl Acad Sci USA 96:3308-3313

* Clapham PJ (2001) Why do baleen whales migrate? A response to Corkeron and Connor. Mar Mamm Sci 17: 432-436

Conn PB, Silber GK (2013) Vessel speed restrictions reduce risk of collision-related mortality for North Atlantic right whales. Ecosphere 4:43

Conversi A, Piontkovski S, Hameed S (2001) Seasonal and interannual dynamics of Calanus finmarchicus in the Gulf of Maine (northeastern US shelf) with reference to the North Atlantic Oscillation. Deep Sea Res II 48: 519-530

Corkeron PJ, Connor RC (1999) Why do baleen whales migrate? Mar Mamm Sci 15:1228-1245

Craig AS, Herman LM, Gabriele CM, Pack AA (2003) Migratory timing of humpback whales (Megaptera novaeangliae) in the central North Pacific varies with age, sex and reproductive status. Behaviour 140: 981-1001

Drinkwater KF, Belgrano A, Borja A, Conversi A and others (2003) The response of marine ecosystems to climate variability associated with the North Atlantic Oscillation. Geophys Monogr 134:211-234

Durbin EG, Campbell RG, Casas MC, Ohman MD, Niehoff B, Runge J, Wagner M (2003) Interannual variation in phytoplankton blooms and zooplankton productivity and abundance in the Gulf of Maine during winter. Mar Ecol Prog Ser 254:81-100

ESRI (2014) ArcGIS Desktop: Release 10.1. Environmental Systems Research Institute, Redlands, CA

Farmer NA, Gowan TA, Powell JR, Zoodsma BJ (2016) Evaluation of alternatives to winter closure of Black Sea bass pot gear: projected impacts on catch and risk of entanglement with North Atlantic right whales Eubalaena glacialis. Mar Coast Fish 8:202-221

Fewster RM, Patenaude NJ (2009) Cubic splines for estimating the distribution of residence time using individual resightings data. In: Thomson DL, Cooch EG, Conroy MJ (eds) Modeling demographic processes in marked populations. Springer, New York, NY, p 393-415

* Firestone J, Lyons SB, Wang C, Corbett JJ (2008) Statistical modeling of North Atlantic right whale migration along the mid-Atlantic region of the eastern seaboard of the United States. Biol Conserv 141:221-232

Fortune SME, Trites AW, Mayo CA, Rosen DAS, Hamilton PK (2013) Energetic requirements of North Atlantic right whales and the implications for species recovery. Mar Ecol Prog Ser 478:253-272

Frasier TR, McLeod BA, Bower RM, Brown MW, White BN (2007) Right whales past and present as revealed by their genes. In: Kraus SD, Rolland RM (eds) The urban whale: North Atlantic right whales at the crossroads. Harvard University Press, Cambridge, MA, p 200-231

* Frasier TR, Hamilton PK, Brown MW, Kraus SD, White BN (2009) Sources and rates of errors in methods of individual identification for North Atlantic right whales. J Mammal 90:1246-1255

Fujiwara M, Caswell H (2001) Demography of the endangered North Atlantic right whale. Nature 414:537-541

Good C (2008) Spatial ecology of the North Atlantic right whale (Eubalaena glacialis). PhD dissertation, Duke University, Durham, NC

* Gowan TA, Ortega-Ortiz JG (2014) Wintering habitat model for the North Atlantic right whale (Eubalaena glacialis) in the southeastern United States. PLOS ONE 9:e95126

*Greene $\mathrm{CH}$, Pershing AJ (2000) The response of Calanus finmarchicus populations to climate variability in the Northwest Atlantic: basin-scale forcing associated with the North Atlantic Oscillation. ICES J Mar Sci 57: 1536-1544

Greene CH, Pershing AJ (2003) The flip-side of the North Atlantic Oscillation and modal shifts in slope-water circulation patterns. Limnol Oceanogr 48:319-322

*Greene CH, Meyer-Gutbrod E, Monger BC, McGarry LP and others (2013) Remote climate forcing of decadalscale regime shifts in Northwest Atlantic shelf ecosystems. Limnol Oceanogr 58:803-816

Gu W, Swihart RK (2004) Absent or undetected? Effects of non-detection of species occurrence on wildlife-habitat models. Biol Conserv 116:195-203

Hain JHW, Ellis SL, Kenney RD, Slay CK (1999) Sightability of right whales in coastal waters of the southeastern United States with implications for the aerial monitoring program. In: Garner GW, Amstrup SC, Laake JL, Manly BFJ, McDonald LL, Robertson DG (eds) Marine mammal survey and assessment methods. AA Balekma, Rotterdam, p 191-207

Hamilton PK, Cooper LA (2010) Changes in North Atlantic right whale (Eubalaena glacialis) cow-calf association times and use of the calving ground: 1993-2005. Mar Mamm Sci 26:896-916 
Hamilton PK, Marx MK, Kraus SD (1995) Weaning in North Atlantic right whales. Mar Mamm Sci 11:386-390

Hamilton PK, Knowlton AR, Marx MK (2007) Right whales tell their own stories: the photo-identification catalog. In: Kraus SD, Rolland RM (eds) The urban whale: North Atlantic right whales at the crossroads. Harvard University Press, Cambridge, MA, p 75-104

Hiby L, Leaper R (2005) DRAFT Progress report on the use of photographic capture histories of individually identified North Atlantic right whales in the Southeast United States to make inferences about whale occurrence in the mid-Atlantic region. www.greater atlantic.fisheries. noaa.gov/protected/shipstrike/new/apr05neit_leaper hiby_report.pdf

Hodge KB, Muirhead CA, Morano JL, Clark CW, Rice AN (2015) North Atlantic right whale occurrence near wind energy areas along the mid-Atlantic US coast: implications for management. Endang Species Res 28: 225-234

Hurrell JW (1995) Decadal trends in the North Atlantic Oscillation: regional temperatures and precipitation. Science 269:676-679

Johnson CL, Leising AW, Runge JA, Head EJH, Pepin P, Plourde S, Durbin EG (2008) Characteristics of Calanus finmarchicus dormancy patterns in the Northwest Atlantic. ICES J Mar Sci 65:339-350

Keller CA, Ward-Geiger LI, Brooks WB, Slay CK, Taylor CR, Zoodsma BJ (2006) North Atlantic right whale distribution in relation to sea-surface temperature in the southeastern United States calving grounds. Mar Mamm Sci 22:426-445

Kendall WL (1999) Robustness of closed capture-recapture methods to violations of the closure assumption. Ecology 80:2517-2525

Kendall WL (2004) Coping with unobservable and misclassified states in capture-recapture studies. Anim Biodivers Conserv 27:97-107

Kendall WL (2006) The 'Robust Design'. In: Cooch E, White GC (eds) Program MARK: a gentle introduction, 5th edn, www.phidot.org/software/mark/docs/book/

Kendall WL, Bjorkland R (2001) Using open robust design models to estimate temporary emigration from capturerecapture data. Biometrics 57:1113-1122

Kendall WL, Stapleton S, White GC, Richardson JI, Pearson $\mathrm{KN}$, Mason P (in press) A multistate open robust design: population dynamics, reproductive effort and phenology of sea turtles from tagging data. Ecol Monogr, doi:10. 1002/ecm.1329

Kenney RD (2007) Right whales and climate change: facing the prospect of a greenhouse future. In: Kraus SD, Rolland RM (eds) The urban whale: North Atlantic right whales at the crossroads. Harvard University Press, Cambridge, MA, p 436-459

Kenney RD, Hyman MAM, Owen RE, Scott GP, Winn HE (1986) Estimation of prey densities required by western North Atlantic right whales. Mar Mamm Sci 2:1-13

Knowlton AR, Kraus SD (2001) Mortality and serious injury of northern right whales (Eubalaena glacialis) in the western North Atlantic Ocean. J Cetacean Res Manag Spec Issue 2:193-208

Knowlton AR, Kraus SD, Kenney RD (1994) Reproduction in North Atlantic right whales (Eubalaena glacialis). Can J Zool 72:1297-1305

Knudsen E, Lindén A, Ergon T, Jonzén N and others (2007) Characterizing bird migration phenology using data from standardized monitoring at bird observatories. Clim Res 35:59-77

Kraus SD, Moore KE, Price CA, Crone MJ, Watkins WA, Winn HE, Prescott JH (1986) The use of photographs to identify individual North Atlantic right whales (Eubalaena glacialis). Rep Int Whal Comm Spec Issue 10: $145-152$

Laake JL (2013) RMark: an R interface for analysis of capture-recapture data with MARK. AFSC Processed Rep 2013-01. Alaska Fisheries Science Center, NOAA, National Marine Fisheries Service, Seattle, WA

*Lebreton JD, Burnham KP, Clobert J, Anderson DR (1992) Modelling survival and testing biological hypotheses using marked animals: a unified approach with case studies. Ecol Monogr 62:67-118

Martin J, Sabatier Q, Gowan TA, Giraud C and others (2016) A quantitative framework for investigating the risk of deadly collisions between marine wildlife and watercraft. Methods Ecol Evol 7:42-50

Mate BR, Nieukirk SL, Kraus SD (1997) Satellite-monitored movements of the northern right whale. J Wildl Manag 61:1393-1405

Mayo CA, Nichols OC, Bessinger MK, Brown MW, Marx MK, Browning CL (2004) Surveillance, monitoring and management of North Atlantic right whales in Cape Cod Bay and adjacent waters - 2004. Final report submitted to the Commonwealth of Massachusetts, Division of Marine Fisheries, Center for Coastal Studies, Provincetown, MA

* Melle W, Runge J, Head E, Plourde S and others (2014) The North Atlantic Ocean as habitat for Calanus finmarchicus: environmental factors and life history traits. Prog Oceanogr 129:244-284

MERCINA (Marine Ecosystem Responses to Climate in the North Atlantic) Working Group (2004) Supply-side ecology response of climate-driven changes in North Atlantic Ocean. Oceanography 17:60-71

*Meyer-Gutbrod EL, Greene CH, Sullivan PJ, Pershing AJ (2015) Climate-associated changes in prey availability drive reproductive dynamics of the North Atlantic right whale population. Mar Ecol Prog Ser 535:243-258

* Miller CA, Best PB, Perryman WL, Baumgartner MF, Moore MJ (2012) Body shape changes associated with reproductive status, nutritive condition and growth in right whales Eubalaena glacialis and E. australis. Mar Ecol Prog Ser 459:135-156

* Murison LD, Gaskin DE (1989) The distribution of right whales and zooplankton in the Bay of Fundy, Canada. Can J Zool 67:1411-1420

NARWC (North Atlantic Right Whale Consortium) (2014) North Atlantic Right Whale Consortium identification database. New England Aquarium, Boston, MA

NASA Goddard Space Flight Center, Ocean Ecology Laboratory, Ocean Biology Processing Group (2014) Seaviewing Wide Field-of-view Sensor (SeaWiFS) Chlorophyll Data; 2014 Reprocessing. NASA OB.DAAC, Greenbelt, MD, USA. https://oceancolor.gsfc.nasa.gov (accessed 13 March 2014)

NMFS (National Marine Fisheries Service) (2005) Recovery plan for the North Atlantic right whale (Eubalaena glacialis). National Marine Fisheries Service, Silver Spring, MD

NMFS (National Marine Fisheries Service) (2014) North Atlantic right whale (Eubalaena glacialis), Source document for the critical habitat designation: a review of information 
pertaining to the definition of 'critical habitat'. U.S. Department of Commerce, National Oceanic and Atmospheric Administration, National Marine Fisheries Service, Office of Protected Resources, Silver Spring, MD

*ttersen G, Planque B, Belgrano A, Post E, Reid PC, Stenseth NC (2001) Ecological effects of the North Atlantic Oscillation. Oecologia 128:1-14

Payne R, Brazier O, Dorsey EM, Perkins JS, Rowntree VJ, Titus A (1983) External features in southern right whales (Eubalaena australis) and their use in identifying individuals. In: Payne R (ed) Communication and behavior of whales. Westview Press, Boulder, CO, p 371-445

Pendleton DE, Sullivan PJ, Brown MW, Cole TVN and others (2012) Weekly predictions of North Atlantic right whale Eubalaena glacialis habitat reveal influence of prey abundance and seasonality of habitat preferences. Endang Species Res 18:147-161

Petruny LM, Wright AJ, Smith CE (2014) Getting it right for the North Atlantic right whale (Eubalaena glacialis): a last opportunity for effective marine spatial planning? Mar Pollut Bull 85:24-32

* Pradel R (2005) Multievent: an extension of multistate capture-recapture models to uncertain states. Biometrics 61: 442-447

R Core Team (2015) R: a language and environment for statistical computing. R Foundation for Statistical Computing, Vienna. www.R-project.org/

Reynolds RW, Smith TM, Liu C, Chelton DB, Casey KS, Schlax MG (2007) Daily high-resolution blended analyses for sea surface temperature. J Clim 20:5473-5496

Roberts JJ, Best BD, Dunn DC, Treml EA, Halpin PN (2010) Marine geospatial ecology tools: an integrated framework for ecological geoprocessing with ArcGIS, Python, R, MATLAB, and C++. Environ Model Softw 25: 1197-1207

Rolland RM, Schick RS, Pettis HM, Knowlton AR, Hamilton PK, Clark JS, Kraus SD (2016) Health of North Atlantic right whales Eubalaena glacialis over three decades: from individual health to demographic and population health trends. Mar Ecol Prog Ser 542:265-282
Rowntree V, Payne R, Schell D (2001) Changing patterns of habitat use by southern right whales (Eubalaena australis) on their nursery ground at Península Valdés, Argentina, and in their long-range movements. J Cetacean Res Manag Spec Issue 2:133-143

Salisbury DP, Clark CW, Rice AN (2016) Right whale occurrence in the coastal waters of Virginia, U.S.A.: endangered species presence in a rapidly developing energy market. Mar Mamm Sci 32:508-519

Schick RS, Kraus SD, Rolland RM, Knowlton AR and others (2013) Using hierarchical Bayes to understand movement, health, and survival in the endangered North Atlantic right whale. PLOS ONE 8:e64166

Shaw AK, Couzin ID (2013) Migration or residency? The evolution of movement behavior and information usage in seasonal environments. Am Nat 181:114-124

* Song H, Ji R, Stock C, Wang Z (2010) Phenology of phytoplankton blooms in the Nova Scotian Shelf-Gulf of Maine region: remote sensing and modeling analysis. J Plankton Res 32:1485-1499

* Stevick PT, Allen J, Berube M, Clapham PJ and others (2003) Segregation of migration by feeding ground origin in North Atlantic humpback whales (Megaptera novaeangliae). J Zool (Lond) 259:231-237

Thomisch K, Boebel O, Clark C, Hagen W, Spiesecke S, Zitterbart D, Van Opzeeland I (2016) Spatio-temporal patterns in acoustic presence and distribution of Antarctic blue whales Balaenoptera musculus intermedia in the Weddell Sea. Endang Species Res 30: 239-253

Vanderlaan ASM, Taggart CT (2009) Efficacy of a voluntary area to be avoided to reduce risk of lethal vessel strikes to endangered whales. Conserv Biol 23:1467-1474

White GC, Burnham KP (1999) Program MARK: Survival estimation from populations of marked animals. Bird Study 46:S120-S139

Winn HE, Price CA, Sorensen PW (1986) The distributional biology of the right whale (Eubalaena glacialis) in the western North Atlantic. Rep Int Whal Comm Spec Issue 10:129-138

Submitted: September 21, 2017; Accepted: May 15, 2018 Proofs received from author(s): July 26, 2018
Editorial responsibility: Jaume Forcada, Cambridge, UK 